\title{
Development of a Mechanistic Model to Represent the Dynamics of Liquid Flow Out of the Rumen and to Predict the Rate of Passage of Liquid in Dairy Cattle
}

\author{
S. Seo, ${ }^{\star 1}$ C. Lanzas, ${ }^{*}$ L. O. Tedeschi, $†$ and D. G. Fox ${ }^{\star}$ \\ *Department of Animal Science, Cornell University, Ithaca, NY 14853 \\ †Department of Animal Science, Texas A\&M University, College Station 77843
}

\begin{abstract}
A mechanistic and dynamic model was developed to represent the physiological aspects of liquid dynamics in the rumen and to quantitatively predict liquid flow out of the reticulorumen (RR). The model is composed of 2 inflows (water consumption and salivary secretion), one outflow (liquid flow through the reticulo-omasal orifice (ROO), and one in-and-out flow (liquid flux through the rumen wall). We assumed that liquid flow through the ROO was coordinated with the primary reticular contraction, which is characterized by its frequency, duration, and amplitude during eating, ruminating, and resting. A database was developed to predict each component of the model. A random coefficients model was used with studies as a random variable to identify significant variables. Parameters were estimated using the same procedure only if a random study effect was significant. The input variables for the model were dry matter intake, body weight, dietary dry matter, concentrate content in the diet, time spent eating, and time spent ruminating. Total water consumption $(\mathrm{kg} / \mathrm{d})$ was estimated as $4.893 \times$ dry matter intake $(\mathrm{kg} /$ d), and $20 \%$ of the water consumed by drinking was assumed to bypass the RR. The salivary secretion rate was estimated to be $210 \mathrm{~g} / \mathrm{min}$ during chewing. During ruminating, however, the salivation rate was assumed to be adjusted for the proportion of liquid in the rumen. Resting salivation was exponentially related to dry matter intake. Liquid efflux through the rumen wall was assumed to be the mean value in the database (4.6 $\mathrm{kg} / \mathrm{h})$. The liquid outflow rate $(\mathrm{kg} / \mathrm{h})$ was assumed to be a product of the frequency of the ROO opening, its duration per opening, and the amount of liquid passed per opening. Simulations of our model suggest that the ROO may open longer for each contraction cycle than had been previously reported (about $3 \mathrm{~s}$ ) and that it is affected by dry matter intake, body weight, and total
\end{abstract}

Received March 23, 2006.

Accepted October 12, 2006.

${ }^{1}$ Corresponding author: swseo@uiuc.edu digesta in the rumen. When compared with 28 observations in 7 experiments, the model accounted for 40 , 70 , and $90 \%$ of the variation, with root mean square prediction errors of $9.25 \mathrm{~kg}, 1.84 \mathrm{~kg} / \mathrm{h}$, and $0.013 \mathrm{~h}^{-1}$ for liquid content in the rumen, liquid outflow rate, and fractional rate of liquid passage, respectively. A sensitivity analysis showed that dry matter intake, followed by body weight and time spent eating, were the most important input variables for predicting the dynamics of liquid flow from the rumen. We conclude that this model can be used to understand the factors that affect the dynamics of liquid flow out of the rumen and to predict the fractional rate of liquid passage from the RR in dairy cattle.

Key words: liquid passage rate, reticulo-omasal orifice opening, ruminal liquid dynamics, modeling

\section{INTRODUCTION}

Liquid in the rumen is very important because it acts as a lubricant and provides a medium for microbes to access feed particles and buffer. Cattle maintain the DM content in the rumen in a range of 14 to $18 \%$ in the dorsal area and 6 to $9 \%$ in the ventral area, depending on the type of diet and DMI (Yokoyama and Johnson, 1988). A faster fractional passage rate of the liquid $\left(\mathbf{K} \mathbf{p l}, \mathrm{h}^{-1}\right)$ was previously associated with more efficient production of microbial protein per unit of DM digested (Evans, 1981). Soluble nutrients move out of the rumen with the liquid. Additionally, ruminal liquid can serve as a vehicle for digesta transport out of the rumen (Faichney et al., 1981; Poppi et al., 1981). Despite its importance, attempts to predict Kpl have not been very successful. Current empirical equations that predict Kpl have failed to explain more than $30 \%$ of the variation in experimental observations (Seo et al., 2006b).

The forestomach of ruminants is separated by a sphincter, the reticulo-omasal orifice (ROO), into 2 primary structures, the reticulorumen $(\mathbf{R R})$ and the omasum (Sellers and Stevens, 1966). The ROO has been shown to play a significant role in regulating the particulate and liquid digesta flow out of the rumen (Balch 
et al., 1951; Mathison et al., 1995), and it is controlled by a complex and coordinated RR contraction. Reticulorumen contractions, characterized by their frequency, duration, and amplitude, are mostly influenced by the chewing behavior of the animal (Mathison et al., 1995); thus, chewing behavior may affect the dynamics of liquid in the rumen. However, no attempt has been reported to quantitatively relate the effect of $R R$ contractions and chewing behavior to the dynamics of liquid flow out of the rumen.

Argyle and Baldwin (1988) previously developed a dynamic model to predict water kinetics in the rumen. However, their model assumes a constant $\mathrm{Kpl}, 0.15 \mathrm{~h}^{-1}$, which does not agree with the summary of experimental data (Owens and Goetsch, 1988; Seo et al., 2006b). The objectives of this study were 1) to develop a mechanistic model that uses the accumulated research knowledge about the mechanisms affecting liquid flow out of the rumen through the $\mathrm{ROO}$ to predict $\mathrm{Kpl}$, and 2) to develop a mathematical model that can be incorporated into mechanistic rumen models for predicting liquid flow out of the rumen.

\section{MATERIALS AND METHODS}

\section{General Procedure}

A model was developed on the concept that an animal controls the movement of liquid from the rumen based on its need for nutrients and on the chemical and physical characteristics of the diet. The model we developed assumes a single ruminal liquid compartment, as shown by Warner and Stacy (1968). It consists of 2 inflows, one in-and-out flow, and one outflow for the liquid phase in the rumen, which is the same as the model of Argyle and Baldwin (1988). We expressed the amount of liquid in kilograms, and the density of the liquid was assumed to be $1.0 \mathrm{~g} / \mathrm{mL}$ at $39^{\circ} \mathrm{C}$, which excludes DM.

Input Variables for the Model. Because the final goal of this study was to develop a model that can be applicable in the field, variables that could easily be measured or estimated in the field were selected for model input variables. The candidate variables were DMI (kg/d), forage DMI (kg/d), concentrate DMI $(\mathrm{kg} / \mathrm{d})$, BW (kg), DMI as a percentage of BW (\% of BW), forage DMI as a percentage of $\mathrm{BW}$ (\% of BW), concentrate DMI as a percentage of $\mathrm{BW}$ ( $\%$ of $\mathrm{BW})$, concentrate content as a percentage of dietary DM (ConcpDM, \% of DM), forage content in the diet (\% of DM), NDF content in forage (\% of DM), forage NDF concentration in the diet (\% of $\mathrm{DM}), \mathrm{ADF}$ concentration in forage (\% of $\mathrm{DM})$, and forage $\mathrm{ADF}$ concentration in the diet (\% of $\mathrm{DM}$ ). Chewing behaviors, including daily time spent eating $(h)$, ruminating $(h)$, and resting $(h)$, were also included to evaluate their effects on liquid dynamics in the rumen.

Parameterization of the Variables. To quantify the relationship between explanatory and response variables, a database was constructed for each component of the model. A random coefficients model, using the MIXED procedure of SAS (SAS Institute, 2002) with studies or experiments as a random variable, was used to parameterize the variables only if the study variable was significant; otherwise, a multiple regression using the GLM procedure of SAS (SAS Institute, 2002) with all fixed effects was used. The detailed method was the same as that described in Seo et al. (2006b). Because the parameters were estimated based on the statistical relationship using a multiple linear regression, their units were defined by the relationships.

\section{Model Development}

Liquid Flow into the Rumen 1: Water Consumption. There were 2 sources of water consumption: free water consumption (not associated with feed) and water content in the diet (associated with feed). An equation to predict the total water consumption was developed from a database consisting of 30 observations (Campling and Freer, 1966; Bines and Davey, 1970; Hartnell and Satter, 1979; Johnson and Combs, 1991; Burgwaldbalstad et al., 1995; Grimaud and Doreau, 1995; Hristov and Broderick, 1996). Many researchers have indicated that water consumption is proportional to DMI (Langhans et al., 1995; NRC, 2001). In our analysis, DMI was the most significant variable for predicting total water consumption; additional variables were not significant. The mean value of $4.893( \pm 0.124) \mathrm{kg}$ of water consumption $/ \mathrm{kg}$ of DMI was estimated $\left(\mathrm{n}=30, \mathrm{R}^{2}=0.93\right)$, which is similar to the $5.22 \mathrm{~kg} / \mathrm{kg}$ reported by Baumont et al. (1993). Some of the water consumed is passed directly into the omasum through the esophageal groove. Woodford et al. (1984) estimated that the proportion of drinking water moving this way was 0.18 and 0.05 when water was withheld for 4.5 and $9 \mathrm{~h}$, respectively, after feeding. Cafe and Poppi (1994) concluded that about of free water consumed is bypassed directly to the omasum when access to water is limited. For our model, we adopted the value of $20 \%$ from Cafe and Poppi (1994) for bypass water, which was applied only to free water consumption.

Therefore, water inflow into the rumen via oral consumption was the sum of 0.8 times the free water consumption and water content in the diet, and can be calculated as follows:

$$
\begin{gathered}
\mathrm{WIC}=0.8 \times[4.893 \times \mathrm{DMI}-(100 / \mathrm{DDM}-1) \times \mathrm{DMI}] \\
+[(100 / \mathrm{DDM}-1) \times \mathrm{DMI}]
\end{gathered}
$$


With some mathematical modifications,

$$
\begin{aligned}
\mathrm{WIC}=[0.8 \times 4.893 & +0.2 \times(100 / \mathrm{DDM}-1)] \\
& \times \mathrm{DMI},
\end{aligned}
$$

where WIC is water inflow into the rumen via oral consumption daily $(\mathrm{kg} / \mathrm{d}), \mathrm{DDM}$ is $\mathrm{DM}$ content in the $\operatorname{diet}(\%)$, and DMI is daily DMI (kg/d).

Liquid Flow into the Rumen 2: Salivary Secretion. The total amount of saliva secreted each day depends on the physical nature and moisture content of feeds consumed (Church, 1988). Because secretory responses are associated with chewing movements, the amount of saliva produced during eating, ruminating, and resting differs (Bartley, 1976).

There are significant differences in the amount of saliva secreted per kilogram of DM among feeds because of their physical and chemical characteristics (Bailey, 1961; Meyer et al., 1964), but the rate of salivation during eating $(\mathrm{g} / \mathrm{min})$ is relatively constant (Beauchemin, 1991). In our model, we assumed that the time spent chewing represents stimulation of saliva secretion by the physical and chemical characteristics of the feedstuff and that the rate of salivary secretion is constant during chewing time. Data were summarized on the rate of salivary secretion during eating. Mean ( \pm SD) saliva secretion during eating was 210 $( \pm 43) \mathrm{g} / \mathrm{min}$ of chewing, based on 24 observation means from 6 studies (Bailey, 1961; Cassida and Stokes, 1986; Beauchemin, 1991; Maekawa et al., 2002a,b; Bowman et al., 2003).

$$
\text { SSR_EAT }=12.60( \pm 2.58) \text {, }
$$

where SSR_EAT is the saliva secretion rate during eating $(\mathrm{kg} / \mathrm{h})$.

Because of a lack of data, we assumed that the basal rate of salivary secretion during ruminating was the same as that during eating. This assumption has been adopted previously (Maekawa et al., 2002b; Bowman et al., 2003). Additionally, we assumed that the rate of salivary secretion during ruminating was affected by the proportion of DM in the ruminal digesta. Because stimulation of tactile and stretch receptors increases salivary secretion (Bailey and Balch, 1961a), the increased liquid proportion in the ruminal digesta (LPR, $\%$ ) would decrease salivary secretion during ruminating.

The analysis of 59 observations from 17 experiments (Campling and Freer, 1966; Bines and Davey, 1970; Hartnell and Satter, 1979; Cassida and Stokes, 1986; Woodford and Murphy, 1988b; Johnson and Combs, 1991, 1992; Okine and Mathison, 1991; Okine et al.,
1993; Kil and Froetschel, 1994; Burgwaldbalstad et al., 1995; Grimaud and Doreau, 1995; Hristov and Broderick, 1996; Maekawa et al., 2002b) gave a strong, significant correlation between daily DMI and the daily mean LPR. Thus, we assumed that the LPR is maintained according to DMI. A random study effect on the intercept was significant:

$$
\begin{aligned}
& \text { MLPR = 91.688 }( \pm 0.509)-0.363( \pm 0.030) \\
& \times \text { DMI }\left(n=59, R^{2}=0.81, \operatorname{RMSPE}=1.11\right),
\end{aligned}
$$

where MLPR is the mean liquid proportion in the ruminal digesta daily (\% of wet digesta).

During a dynamic simulation, the LPR at an instant time point, calculated as the liquid content in the rumen divided by the total ruminal digesta times 100 , is compared with the daily mean value estimated by using equation [3]. The basal rate of salivary secretion during ruminating is then adjusted for the difference in LPR as shown in equation [4]. The coefficient for the effect of the difference in LPR on salivary secretion during ruminating was arbitrarily assumed to be 2.4 to balance the sensitivity of the model to the value. The equation used in this model to predict the rate of salivary secretion during ruminating was as follows:

$$
\text { SSR_RUM }=12.60+2.4 \times(\text { MLPR }- \text { ILPR }),
$$

where SSR_RUM is the saliva secretion rate during rumination $(\mathrm{kg} / \mathrm{h})$, MLPR is the predicted daily mean liquid proportion in the ruminal digesta (\%), and ILPR is the predicted instant liquid proportion in the ruminal digesta at an actual time point during simulation (\%).

Saliva secretion during resting is quite variable among animals, among sampling times within an animal, and among intakes and types of diets (Bailey and Balch, 1961b). A database was constructed to obtain quantitative relationships with other variables for the rate of salivary secretion during resting. This database consisted of 39 observation means from 8 studies (Bailey and Balch, 1961b; Meyer et al., 1964; Putnam et al., 1965; Putnam et al., 1966; Cassida and Stokes, 1986; Maekawa et al., 2002a,b; Bowman et al., 2003). The exponential equation with DMI was the best-fit equation. With this equation, we assumed that basal saliva secretion during resting, which is the y-intercept of the equation, was $21.1 \mathrm{~g} / \mathrm{min}$ and that the rate of increase in salivation was proportional to the rate of increase in DMI independent of any other variables:

$$
\text { SSR_RES }=1.266( \pm 0.064) \times \operatorname{EXP}[0.091
$$

$( \pm 0.004) \times \mathrm{DMI}]\left(\mathrm{n}=30, \mathrm{R}^{2}=0.93, \mathrm{RMSPE}=0.80\right)$ 
where SSR_RES is the saliva secretion rate during resting $(\mathrm{kg} / \mathrm{h})$ and DMI is the DM intake $(\mathrm{kg} / \mathrm{d})$

Liquid Fluxes Through the Rumen Wall. A data set was constructed to quantify the amount of liquid flux through the rumen wall (Cassida and Stokes, 1986; Canale et al., 1988; Woodford and Murphy, 1988b; Okine et al., 1989; Okine and Mathison, 1991; Kil and Froetschel, 1994; Grimaud and Doreau, 1995; Hristov and Broderick, 1996; Maekawa et al., 2002b). In the data set, the liquid content in the rumen (LCR, $\mathrm{kg}$ ) was determined by emptying the rumen, and the rate of liquid passage was estimated using markers, collected through the ruminal fistula. Net water flux through the rumen wall was calculated by subtracting the liquid outflow from the total liquid inflow; thus, a positive sign represents net liquid absorption through the rumen wall. The liquid outflow rate $(\mathrm{kg} / \mathrm{d})$ was computed by multiplying $\mathrm{LCR}$ by $\mathrm{Kpl}\left(\mathrm{h}^{-1}\right)$ times 24 . The total liquid inflow is the sum of water intake, water from feed, and salivation. If water consumption was not reported, it was estimated by equation [1]. Free water intake was corrected for bypass directly into the omasum. In the data set, only Maekawa et al. (2002b) measured salivary secretion. Salivation was estimated using equations [2] and [5]. The rate of salivation during ruminating was assumed to be the same as that during eating. If chewing activities were not reported, the mean chewing $(13.17 \mathrm{~h} / \mathrm{d})$ and resting times $(10.83 \mathrm{~h} /$ d) determined for dairy cows were assumed (Beauche$\min , 1991$ ).

Mean liquid flux out of the rumen through the rumen wall was estimated to be $112( \pm 48) \mathrm{kg}$ daily, and the value calculated from the measured LCR and Kpl showed that there was net water loss through the rumen wall daily. This is consistent with the finding that overall daily osmotic pressure is lower in the rumen than in plasma, and as a result, water is absorbed (Lopez et al., 2003). There was no acceptable equation for predicting liquid flux through the rumen wall with variables that are commonly measured or calculated in the field. Therefore, we assumed that liquid is absorbed through the rumen wall at a rate of $4.6 \mathrm{~kg} / \mathrm{h}$ :

$$
\mathrm{LFRW}=4.6( \pm 2.00),
$$

where LFRW is liquid flux through the rumen wall $(\mathrm{kg} / \mathrm{h})$.

Liquid Outflow. The ROO plays a significant role in the regulation of particulate and liquid digesta flow out of the rumen (Balch et al., 1951; Mathison et al., 1995), and it is controlled by a complex and coordinated $\mathrm{RR}$ contraction. The lack of digesta passage in animals with a rumen in stasis (Balch and Campling, 1962) indicated that $R R$ contractions are necessary for the passage of digesta from the RR. The amount of water flow per unit of time can be calculated as follows: liquid outflow rate $(\mathrm{kg} / \mathrm{h})=\mathrm{ROO}$ opening frequency $(1 / \mathrm{min}) \times$ duration of ROO opening per opening $(\mathrm{s}) \times$ the amount of liquid passed per ROO opening second $(\mathrm{g} / \mathrm{s}) \times 60 \mathrm{~min} /$ $\mathrm{h} \times 1 / 1,000(\mathrm{~kg} / \mathrm{g})$.

The opening of the ROO and digesta transfer have been assumed to occur in accordance with the primary reticular contraction (PRC; Kelly et al., 1991; Froetschel et al., 1997; Okine et al., 1998). A database was constructed to quantify the RR motility and generate the best prediction models. A total of 74 observations in 19 experiments that measured the reticular motility of cattle during eating, ruminating, and resting separately were obtained from 12 scientific journal articles (Balch, 1952; Freer et al., 1962; Freer and Campling, 1965; Campling and Freer, 1966; Bines and Davey, 1970; Dracy et al., 1972; Norgaard, 1989; Okine and Mathison, 1991; Johnson and Combs, 1992; Miaron and Christopherson, 1992; Okine et al., 1993; Okine et al., 1994). Table 1 summarizes the descriptive statistics in the database.

Frequency of Primary Reticular Contractions. In normal situations, opening of the ROO is accompanied by PRC (Balch et al., 1951; Stevens et al., 1960; Kelly et al., 1991). Therefore, the frequency of ROO opening was assumed to be the same as that of reticular contractions. Empirical equations were developed to predict the frequency of PRC during eating, ruminating, and resting. None of the candidate variables were significant for estimating the frequency of PRC during rumination; therefore, a mean value was used:

$$
\begin{gathered}
\text { FRQ_EAT }=1.345( \pm 0.045)+0.035( \pm 0.006) \\
\times \text { DMI/T_EAT }+0.003( \pm 0.001) \\
\times \text { ConcpDM }\left(\mathrm{n}=60, \mathrm{R}^{2}=0.37, \mathrm{RMSPE}=0.16\right), \\
\text { FRQ_RUM }=1.122( \pm 0.036) \\
(\mathrm{n}=72, \mathrm{RMSPE}=0.20), \text { and } \\
\text { FRQ_RES }=1.494( \pm 0.042)-0.026 \\
( \pm 0.004) \times \text { T_RES }\left(\mathrm{n}=60, \mathrm{R}^{2}=0.56, \mathrm{RMSPE}=0.14\right),
\end{gathered}
$$

where FRQ_EAT, FRQ_RUM, and FRQ_RES are the frequency of PRC during eating, ruminating, and resting, respectively (1/min); DMI is DM intake (kg); T_EAT is time spent eating $(\mathrm{h} / \mathrm{d})$; ConcpDM is the concentrate content in the diet (\% of DM); and T_RES is the time spent resting $(\mathrm{h} / \mathrm{d})$.

Duration of ROO Opening. Only a few studies have actually measured the duration of ROO opening. By analyzing the data from Kelly et al. (1991) and 
SEO ET AL.

Table 1. Descriptive statistics for the database used to develop equations to predict primary reticular motility

\begin{tabular}{|c|c|c|c|c|}
\hline Item & No. & Mean & SD & $\mathrm{CV}, \%$ \\
\hline \multicolumn{5}{|l|}{ Reticular motility } \\
\hline Frequency during eating, $\min ^{-1}$ & 74 & 1.56 & 0.18 & 11.3 \\
\hline Duration during eating, $\mathrm{s}$ & 21 & 5.48 & 0.69 & 12.6 \\
\hline Amplitude during eating, $\mathrm{mmHg}$ & 21 & 9.78 & 3.41 & 34.8 \\
\hline Frequency during ruminating, $\min ^{-1}$ & 72 & 1.12 & 0.20 & 17.6 \\
\hline Duration during ruminating, $\mathrm{s}$ & 21 & 6.37 & 2.23 & 35.1 \\
\hline Amplitude during ruminating, $\mathrm{mmHg}$ & 21 & 9.31 & 3.24 & 34.8 \\
\hline Frequency during resting, $\min ^{-1}$ & 74 & 1.13 & 0.20 & 17.4 \\
\hline Duration during resting, $\mathrm{s}$ & 21 & 5.94 & 0.50 & 8.4 \\
\hline Amplitude during resting, $\mathrm{mmHg}$ & 21 & 11.84 & 3.62 & 30.6 \\
\hline \multicolumn{5}{|l|}{ Animal and diet } \\
\hline BW, kg & 38 & 576.6 & 103.1 & 17.9 \\
\hline DMI, kg & 73 & 10.7 & 5.6 & 52.6 \\
\hline Forage DMI, kg & 73 & 8.1 & 3.8 & 46.6 \\
\hline Concentrate DMI, kg & 73 & 2.6 & 4.1 & 160.0 \\
\hline NDF intake, kg & 24 & 6.8 & 1.6 & 23.9 \\
\hline Concentrate content in the diet, $\mathrm{g} / \mathrm{kg}$ of $\mathrm{DM}$ & 73 & 173 & 283 & 163.6 \\
\hline Dietary DM, g/kg & 40 & 806 & 147 & 18.3 \\
\hline Dietary $\mathrm{CP}, \mathrm{g} / \mathrm{kg}$ of $\mathrm{DM}$ & 40 & 135 & 55 & 40.5 \\
\hline Dietary NDF, g/kg of DM & 24 & 476 & 175 & 36.7 \\
\hline Dietary ADF, g/kg of DM & 25 & 270 & 109 & 40.2 \\
\hline Dietary acid-detergent lignin, $\mathrm{g} / \mathrm{kg}$ of $\mathrm{DM}$ & 25 & 47 & 18 & 37.8 \\
\hline Forage NDF, g/kg of DM & 12 & 638 & 114 & 17.9 \\
\hline Forage ADF, g/kg of DM & 12 & 386 & 59 & 15.3 \\
\hline Forage acid-detergent lignin, $\mathrm{g} / \mathrm{kg}$ of $\mathrm{DM}$ & 12 & 61 & 17 & 27.3 \\
\hline Ruminal DM, kg & 28 & 9.4 & 3.7 & 39.5 \\
\hline Ruminal liquid, kg & 25 & 65.6 & 11.4 & 17.4 \\
\hline Total ruminal digesta, $\mathrm{kg}$ & 28 & 68.0 & 26.3 & 38.7 \\
\hline \multicolumn{5}{|l|}{ Chewing activity } \\
\hline Time spent chewing, $\mathrm{h}$ & 60 & 9.05 & 4.04 & 44.6 \\
\hline Time spent eating, $\mathrm{h}$ & 60 & 3.36 & 1.83 & 54.5 \\
\hline Time spent ruminating, $\mathrm{h}$ & 60 & 5.69 & 2.76 & 48.4 \\
\hline Time spent resting, h & 60 & 14.94 & 4.04 & 27.1 \\
\hline
\end{tabular}

Froetschel et al. (1997), we found that the ROO was opened $0.52( \pm 0.09)$ of the total duration of the PRC. Because this value was not significantly different from 0.50 , we assumed that the opening of the ROO lasted for half the duration of the biphasic PRC. Because of a lack of information, no significant equations could be derived for predicting the duration of PRC. The variation in the duration of biphasic PRC was relatively small (Table 1), which means it may be precisely controlled. Therefore, we decided to use the mean values in the database. Using the mean values of 21 observations, we estimated the duration of the ROO opening per PRC, which is half of duration of biphasic PRC, as $2.74( \pm 0.35), 3.18( \pm 1.12)$, and $2.97( \pm 0.25)$ s during eating, ruminating, and resting, respectively.

Liquid Flow per ROO Opening. The amount of liquid flow per unit of time of ROO opening $(\mathrm{g} / \mathrm{s})$ can be estimated as follows (detailed calculations are given in the Appendix):

$$
\mathrm{LFRO}=5.0 \times \sqrt{\mathrm{AMP}}
$$

where LFRO is the liquid flow per second of ROO opening $(\mathrm{g} / \mathrm{s})$ and AMP is the amplitude of the second phase of the primary reticular contraction $(\mathrm{mmHg})$.

As for the duration of PRC, we could not find significant equations to predict the amplitude of the second phase of PRC. Thus, we used the mean values in our database containing 21 observations. The values were $9.780( \pm 3.407), 9.305( \pm 3.235)$, and $11.837( \pm 3.616)$ $\mathrm{mmHg}$ during eating, ruminating, and resting, respectively. Revision based on further research is needed to predict the liquid flow per ROO opening more accurately.

Adjustment Factor for Opening of the ROO. A preliminary simulation with the data from a series of papers by Taylor and Allen (2005a,b,c) showed that predictions substantially underestimated the observations. Liquid velocity, ROO openings, or both should have increased more than 3 -fold to achieve the same liquid outflow rate that was measured. Because the amplitude of reticular contraction in the database was measured with fistulated animals, it might be underestimated (Ruckebusch, 1988). Holteniu (1971) reported 
Table 2. Descriptive statistics for the database used for developing equations to adjust the opening of the reticulo-omasal orifice (ROO)

\begin{tabular}{llcccc}
\hline Item & $\mathrm{N}$ & Mean & $\mathrm{SD}$ & Min. & Max. \\
\hline BW, kg & 15 & 703 & 121 & 579 & 886 \\
DMI, kg/d & 15 & 18.2 & 5.7 & 11.0 & 25.5 \\
Concentrates in the diet, g/kg of DM & 15 & 325 & 242 & 0 & 600 \\
Eating time, min & 15 & 4.53 & 1.17 & 2.75 & 6.63 \\
Ruminating time, min & 15 & 7.60 & 2.10 & 3.40 & 10.53 \\
Resting time, min & 15 & 11.87 & 2.95 & 7.83 & 17.67 \\
Ruminal DM, kg & 15 & 11.3 & 1.7 & 8.9 & 15.0 \\
Ruminal liquid, kg & 15 & 66.8 & 8.7 & 54.0 & 80.7 \\
Total ruminal digesta, kg & 15 & 78.1 & 10.1 & 63.8 & 95.6 \\
Proportion of ruminal liquid, g/kg & 15 & 855 & 12 & 839 & 880 \\
Liquid passage rate, 1/h & 15 & 0.129 & 0.052 & 0.064 & 0.206 \\
Liquid flow, kg/h & 15 & 8.56 & 3.50 & 4.39 & 14.42 \\
Estimated ROO opening adjustment factor & 15 & 2.36 & 0.93 & 1.20 & 3.90 \\
\hline
\end{tabular}

that fistulation lowered the amplitude of reticular contraction ( 8 and $25 \%$ reduction in the first and second reticular contraction, respectively), whereas the frequency and duration of contractions were not affected. However, based on equation [10], the pressure gradient needed to be about $100 \mathrm{mmHg}$ to increase the liquid velocity 3.16-fold. Although Dracy et al. (1972) reported 116,78 , and $149 \mathrm{mmHg}$ for the peak amplitudes during eating, ruminating, and resting, respectively, in intact animals, underestimated amplitude should not be the main reason for the difference 1) because fistulated animals showed digestion and passage kinetics similar to those of intact animals, and 2) because faster than 15 $\mathrm{cm} / \mathrm{s}$ of liquid velocity caused by an increased pressure gradient seemed to be unrealistic, compared with the speed of reticular displacement during the first contraction, which was measured by ultrasound (Braun and Gotz, 1994; $5.4 \pm 1.32 \mathrm{~cm} / \mathrm{s}$ ). Because there are some reports that the ROO opens more frequently than once per PRC (Mathison et al., 1995), we assumed that the ROO should be open longer per each PRC to increase the liquid flow rate.

A database was used to develop a factor to adjust the duration of the ROO opening per PRC for variation in the input variables. In the databases, BW, DMI, concentrate content in the diet, and chewing activities were measured; the DM and liquid contents in the rumen were determined by emptying the rumen; and the rate of liquid passage was estimated using markers, collected through the ruminal fistula. The database included a total of 15 observations in 4 experiments (Woodford and Murphy, 1988b; Okine and Mathison, 1991; Fernandez et al., 2004; Taylor and Allen, 2005a,b,c). Table 2 shows descriptive statistics for the database. The analysis indicated that, on average, the ROO should have opened $2.36( \pm 0.93)$ times more than the mean values shown in equations [10], [11], and [12] in the database. This result implied that the ROO opens more frequently than the PRC, longer than the duration of the second phase of PRC, or both. The equation developed for predicting the adjustment factor for ROO opening using the GLM procedure of SAS (SAS Institute, 2002) is as follows:

$$
\begin{gathered}
\mathrm{AF}=-6.798( \pm 1.370)+0.210( \pm 0.022) \times \mathrm{DMI} \\
+0.003( \pm 0.001) \times \mathrm{BW}+0.039 \\
( \pm 0.007) \times \mathrm{TCR}\left(\mathrm{n}=15, \mathrm{R}^{2}=0.95, \mathrm{RMSPE}=0.27\right)
\end{gathered}
$$

where $\mathrm{AF}$ is the adjustment factor for opening of the ROO, DMI is DM intake (kg), BW is the animal's full BW $(\mathrm{kg})$, and TCR is total contents in the rumen $(\mathrm{kg})$. Dry matter intake, BW, and total ruminal digesta were significantly correlated with the adjustment factor for opening of the ROO, resulting in more liquid flowing out of the rumen through the ROO, with variation in these inputs.

The final equation to predict LOFR through the ROO is as follows:

$$
\mathrm{LOFR}=0.3 \times \mathrm{FRQ} \times \mathrm{DUR} \times \mathrm{AF} \times \sqrt{\mathrm{AMP}}
$$

where LOFR is the liquid outflow rate $(\mathrm{kg} / \mathrm{h}), \mathrm{FRQ}$ is the frequency of the primary reticular contraction $\left(\mathrm{min}^{-}\right.$ ${ }^{1}$ ), DUR is the duration of the ROO opening at the second phase of primary reticular contractions, AF is the adjustment factor for opening of the ROO, and AMP is the amplitude of the second phase of primary reticular contractions.

\section{Model Simulation and Evaluation}

The model was evaluated in 2 phases. In the first phase, the liquid outflow component of the model was evaluated. The revised liquid outflow component of the model with equation [12] incorporated was evaluated, 
SEO ET AL.

Table 3. Data used for the sensitivity analysis of predictions of the liquid outflow rate and fractional liquid passage rate to variation in the frequency and amplitude of the primary reticular contraction and duration of reticulo-omasal orifice opening per one cycle of primary reticular contraction

\begin{tabular}{|c|c|c|c|c|c|c|c|}
\hline Item & Activity & & Study $1^{1}$ & Study 2 & Study 3 & Study 4 & Study 5 \\
\hline \multirow[t]{6}{*}{ Frequency, $\min ^{-1}$} & \multirow[t]{2}{*}{ Eating } & $\operatorname{Min}^{2}$ & 1.52 & 1.47 & 1.59 & 1.32 & 1.45 \\
\hline & & Max. & 1.86 & 1.79 & 1.94 & 1.62 & 1.77 \\
\hline & \multirow[t]{2}{*}{ Ruminating } & Min. & & & 1.01 & & \\
\hline & & Max. & & & 1.23 & & \\
\hline & \multirow{2}{*}{ Resting } & Min. & 1.08 & 1.08 & 0.93 & 0.96 & 1.11 \\
\hline & & Max. & 1.32 & 1.32 & 1.13 & 1.17 & 1.36 \\
\hline \multirow[t]{6}{*}{ Duration, s } & \multirow[t]{2}{*}{ Eating } & Min. & 7.18 & 7.16 & 3.54 & 2.50 & 5.35 \\
\hline & & Max. & 8.77 & 8.75 & 4.33 & 3.05 & 6.54 \\
\hline & \multirow[t]{2}{*}{ Ruminating } & Min. & 8.35 & 8.33 & 4.12 & 2.91 & 6.23 \\
\hline & & Max. & 10.21 & 10.18 & 5.04 & 3.55 & 7.61 \\
\hline & \multirow[t]{2}{*}{ Resting } & Min. & 7.78 & 7.76 & 3.84 & 2.71 & 5.80 \\
\hline & & Max. & 9.51 & 9.48 & 4.69 & 3.31 & 7.09 \\
\hline \multirow[t]{6}{*}{ Amplitude, mmHg } & \multirow[t]{2}{*}{ Eating } & Min. & & & 8.80 & & \\
\hline & & Max. & & & 10.76 & & \\
\hline & \multirow[t]{2}{*}{ Ruminating } & Min. & & & 8.41 & & \\
\hline & & Max. & & & 10.27 & & \\
\hline & \multirow[t]{2}{*}{ Resting } & Min. & & & 10.67 & & \\
\hline & & Max. & & & 13.04 & & \\
\hline
\end{tabular}

\footnotetext{
${ }^{1}$ Study 1, treatment 1 in Taylor and Allen (2000a,b,c); study 2, treatment 4 in Yang et al. (2001); study 3, treatment 3 in Woodford and Murphy (1988b); study 4, treatment 1 in Okine and Mathison (1991); study 5, treatment 4 in Maekawa et al. (2002b).

${ }^{2}$ The minimum and maximum values are $-10 \%$ and $+10 \%$, respectively, of the mean from the mean estimates for each simulation.
}

with a total of 17 observations in 4 experiments in an independent database (Woodford and Murphy, 1988a; Yang et al., 2001; Maekawa et al., 2002b; Voelker and Allen, 2003a,b; ). Simulations with a time step of a day were conducted with a spreadsheet version of the model. Dry matter, liquid, and total digesta contents in the rumen were included as input variables in the simulation.

In the second phase, the final complete model was simulated and evaluated. Dynamic simulations were conducted with Vensim professional version 5.0a (Ventana Systems Inc., Harvard, MA). The fractional passage rate of DM in the rumen was assumed to be DMI/ mean ruminal $\mathrm{DM} / 24$. The simulation assumed that an animal consumed the diet in 12 equal meals. The duration of each meal was estimated by dividing the eating time by 12 . The first feeding started at $1 \mathrm{~h}$ after the simulation began. Water from the diet was consumed during each meal and free water was drunk right after the meal for $1.32 \mathrm{~min}$ (about $16 \mathrm{~min} / \mathrm{d}$; Dado and Allen, 1995). Rumination (daily ruminating time divided by 12) started 30 min after each of the 12 meals. Integration was conducted by the Euler method with a time step of $1 \mathrm{~min}$, as suggested by Sauvant et al. (1996). Simulations lasted $120 \mathrm{~h}$ to ensure that a stable oscillation was reached, and it was typically reached in 48 to $72 \mathrm{~h}$. Simulation results from 96 to $120 \mathrm{~h}$, with 0.1 -h intervals, were collected for evaluation. Predictions from the model were compared with the observations in the combined databases used to develop and evaluate the liquid outflow component of the model. The data from Fernandez et al. (2004) were omitted because they lacked information on the DM content in the diet.

The coefficient of determination $\left(\mathrm{R}^{2}\right)$ was used to assess the precision of the model. The root mean square prediction error (RMSPE), calculated by the square root of the mean of the square of the observed minus predicted value (Bibby and Toutenburg, 1977), was used to determine the accuracy of the model.

Residual analyses were also conducted to assess the biases of the model prediction, as proposed by St-Pierre (2003). The predicted values were centered around the mean predicted value before the residuals were regressed on the predicted values.

\section{Sensitivity Analysis}

Sensitivity analyses were also conducted in 2 phases. In the first phase, the sensitivity of model predictions for liquid outflow rate and $\mathrm{Kpl}$ to the frequency, duration, and amplitude of contraction was analyzed with a Monte Carlo simulation technique using @Risk version 4.5 (Palisade Corporation, Newfield, NY). The distribution of the input variables was assumed to be uniform, with $\pm 10 \%$ from the mean as the minimum and maximum values. The simulations were conducted with 5 observations from 5 experiments in the database [study 1, treatment 1 in Taylor and Allen (2005a,b,c); 
Table 4. Description and units of the abbreviations used in the final model equations developed to predict the liquid passage rate

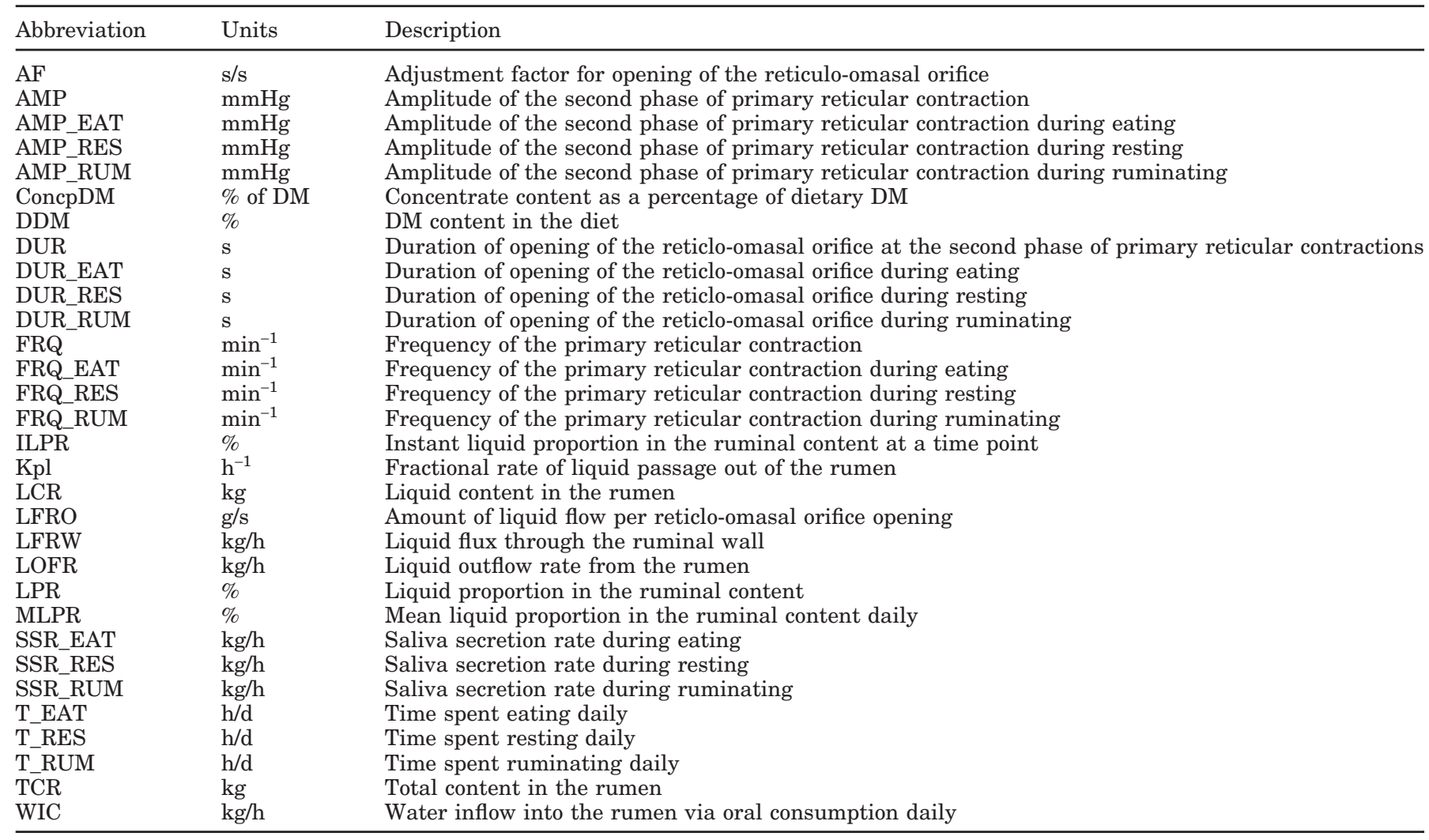

study 2, treatment 4 in Yang et al. (2001); study 3, treatment 3 in Woodford and Murphy (1988b); study 4, treatment 1 in Okine and Mathison (1991); study 5, treatment 4 in Maekawa et al. (2002b)]. Table 3 shows the variations in inputs for each simulation.

In the second phase, the sensitivity of the model predictions for liquid outflow rate and Kpl to input variables of the model was also conducted with a Monte Carlo simulation technique using Vensim professional version 5.0a (Ventana Systems Inc., Harvard, MA). The data from the control treatment in Taylor and Allen (2005a,b,c) was used to run the simulations. The input variables included BW $(\mathrm{kg})$, DMI $(\mathrm{kg} / \mathrm{d})$, concentrate content in the diet (\% of DM), DM content in the diet (\% of DM), eating time (h), and ruminating time (h). The distribution of the input variables was assumed to be uniform, with $\pm 10 \%$ from the mean as the minimum and maximum values. One variable at a time was sampled from each distribution. Iterations of the simulation were continued 200 times for a time frame of 0 to $48 \mathrm{~h}$.

\section{RESULTS}

All variable names used in the equations for the final model that predicted the liquid passage rate are de- scribed in Table 4, and the equations in the final model are listed in Table 5.

\section{Model Prediction of Ruminal Liquid Outflow Through the ROO: The First Phase}

Figure 1 shows regression plots of observed on predicted values for the liquid outflow rate and Kpl through the ROO when we used the measured liquid content in the rumen in the database. The $\mathrm{R}^{2}$ of predictions were 0.89 and 0.83 , and the RMSPE were 0.80 and 0.012 for the liquid outflow rate and $\mathrm{Kpl}$, respectively. When residuals (observed minus predicted outflow) were regressed on predicted liquid outflows that were centered around the mean predicted value, the intercept $(0.49 \pm$ $0.15)$ was different from $0(P<0.05)$, whereas the slope $(-0.10 \pm 0.08)$ was not significantly different from $0(P$ $>0.05)$. For the liquid passage rate, both the intercept $(0.007 \pm 0.002)$ and the slope $(-0.20 \pm 0.09)$ were significantly different from $0(P<0.05)$, which meant there were mean and slope biases.

Despite these small biases in predicting the liquid passage rate, the model predicted the liquid outflow rate and fractional liquid passage rate accurately (A and $B$, respectively, in Figure 1) when the amount of 
SEO ET AL.

Table 5. Equations used in the model to predict liquid passage from the rumen ${ }^{1}$

\begin{tabular}{|c|c|c|c|}
\hline Equation no. & Variable & Units & Equation \\
\hline [1] & WIC & $\mathrm{kg} / \mathrm{d}$ & $\begin{array}{l}{[0.8 \times 4.893+0.2 \times(100 / \mathrm{DDM}-1)] \times \mathrm{DMI}} \\
\text { unitless, } \mathrm{kg} / \mathrm{kg}, \text { unitless, \%, unitless }\end{array}$ \\
\hline [2] & SSR_EAT & $\mathrm{kg} / \mathrm{h}$ & $\begin{array}{l}12.60 \\
\mathrm{~kg} / \mathrm{h}\end{array}$ \\
\hline [3] & MLPR & $\%$ & $\begin{array}{l}91.688-0.363 \times \mathrm{DMI} \\
\%, \% /(\mathrm{kg} / \mathrm{d})\end{array}$ \\
\hline [4] & SSR_RUM & $\mathrm{kg} / \mathrm{h}$ & $\begin{array}{l}12.60+40 \times(\mathrm{MLPR}-\mathrm{ILPR}) \\
\mathrm{kg} / \mathrm{h}, \mathrm{kg} / \mathrm{h}\end{array}$ \\
\hline [5] & SSR_RES & $\mathrm{kg} / \mathrm{h}$ & $\begin{array}{l}1.266 \times \mathrm{e}^{(0.091 \times \mathrm{DMI})} \\
\mathrm{kg} / \mathrm{h}, 1 /(\mathrm{kg} / \mathrm{d})\end{array}$ \\
\hline [6] & LFRW & $\mathrm{kg} / \mathrm{h}$ & $\begin{array}{l}4.6 \\
\mathrm{~kg} / \mathrm{h}\end{array}$ \\
\hline [7] & FRQ_EAT & $\min ^{-1}$ & $\begin{array}{l}1.345+0.035 \times \mathrm{DMI} / \mathrm{T} \_ \text {EAT }+0.003 \times \mathrm{ConcpDM} \\
1 / \mathrm{min},(\mathrm{d} \cdot \mathrm{h}) /(\mathrm{kg} \cdot \mathrm{min}), 1 / \mathrm{min}\end{array}$ \\
\hline [8] & FRQ_RUM & $\min ^{-1}$ & $\begin{array}{l}1.122 \\
1 / \mathrm{min}\end{array}$ \\
\hline [9] & FRQ_RES & $\min ^{-1}$ & $\begin{array}{l}1.494-0.026 \times \mathrm{T} \_\mathrm{RES} \\
1 / \mathrm{min}, 1 /(\mathrm{min} \cdot \mathrm{h})\end{array}$ \\
\hline [10] & LFRO & $\mathrm{g} / \mathrm{s}$ & $\begin{array}{l}5 \times \mathrm{AMP}^{1 / 2} \\
\mathrm{~g} /\left(\mathrm{s} \cdot \mathrm{mmHg}^{1 / 2}\right)\end{array}$ \\
\hline [11] & $\mathrm{AF}$ & $\mathrm{s} / \mathrm{s}$ & $\begin{array}{l}-6.798+0.210 \times \mathrm{DMI}+0.003 \times \mathrm{BW}+0.039 \times \mathrm{TCR} \\
\text { unitless, } \mathrm{d} / \mathrm{kg}, 1 / \mathrm{kg}, 1 / \mathrm{kg}\end{array}$ \\
\hline [12] & LOFR & $\mathrm{kg} / \mathrm{h}$ & $\begin{array}{l}0.3 \times \mathrm{FRQ} \times \mathrm{DUR}^{2} \times \mathrm{AF} \times \mathrm{AMP}^{1 / 23} \\
\text { unitless }\end{array}$ \\
\hline [13] & $\mathrm{Kpl}$ & $\mathrm{h}^{-1}$ & LOFR/LCR \\
\hline
\end{tabular}

${ }^{1}$ The units of parameters are shown in order under each equation.

${ }^{2}$ Values for DUR were 2.74, 3.18, and $2.97 \mathrm{~s}$ during eating, ruminating, and resting, respectively.

${ }^{3}$ Values for AMP were 9.780, 9.305, and $11.837 \mathrm{mmHg}$ during eating, ruminating, and resting, respectively.

digesta content in the rumen was known. We concluded that the ROO opening varied according to the amount of rumen digesta content, DMI, and BW, which controls the amount of liquid flow out of the rumen.

\section{Model Prediction of Liquid Dynamics in the Rumen: The Second Phase}

With a total of 28 observations in 7 experiments, the final, complete model explained 40,70 , and $90 \%$ of variations in the liquid pool in the rumen and in the liquid outflow rate and $\mathrm{Kpl}$ from the rumen, respectively. Figure 2 shows the results of the regression of observed values on predicted values for each prediction following dynamic simulations with the final model. The RMSPE of the predictions were 9.25, 1.84, and 0.013 for the liquid pool in the rumen and the liquid outflow rate and liquid passage rate from the rumen, respectively. The residual analysis (Figure 3) indicated that none of the predictions had a slope bias, but the mean bias was significant in all the cases.

\section{Model Sensitivity Analysis}

Table 6 shows the results from the sensitivity analysis of predictions for liquid outflow to variations in characteristics of the PRC. Although there were numerical differences, variations from the mean were relatively constant in predicting the liquid outflow rate and $\mathrm{Kpl}$ from the rumen. The average coefficient of variation was $5.6 \%$, with a range between 5.17 and $6.51 \%$. Variability increased when the resting time was relatively longer. Results from the sensitivity analysis were similar in all the simulations. The duration and frequency of ROO opening during resting were the most important variables in predicting both the liquid outflow rate and $\mathrm{Kpl}$ of the liquid. In all the simulations except for study 5 (treatment 4 in Maekawa et al., 2002b), the frequency, duration, and amplitude during eating and amplitude during ruminating were the least important variables. Table 7 shows the relative ranking according to the standardized regression coefficient of inputs from the simulation with data from the control treatment of Taylor and Allen (2005a,b,c). This seemed to be due to the relative proportion of the activities. Because the resting time is normally longer than the eating and ruminating times, predictions of the model may be the most sensitive to contraction characteristics during the resting time. The sensitivity analysis clearly showed that the opening of the ROO in terms of frequency and duration was more important in controlling liquid outflow from the rumen than were pressure gradient and even velocity of the fluid, assuming that the area of ROO opening does not vary much in mature animals.

The sensitivity analysis of the complete model to input variables showed that the model predictions for the 

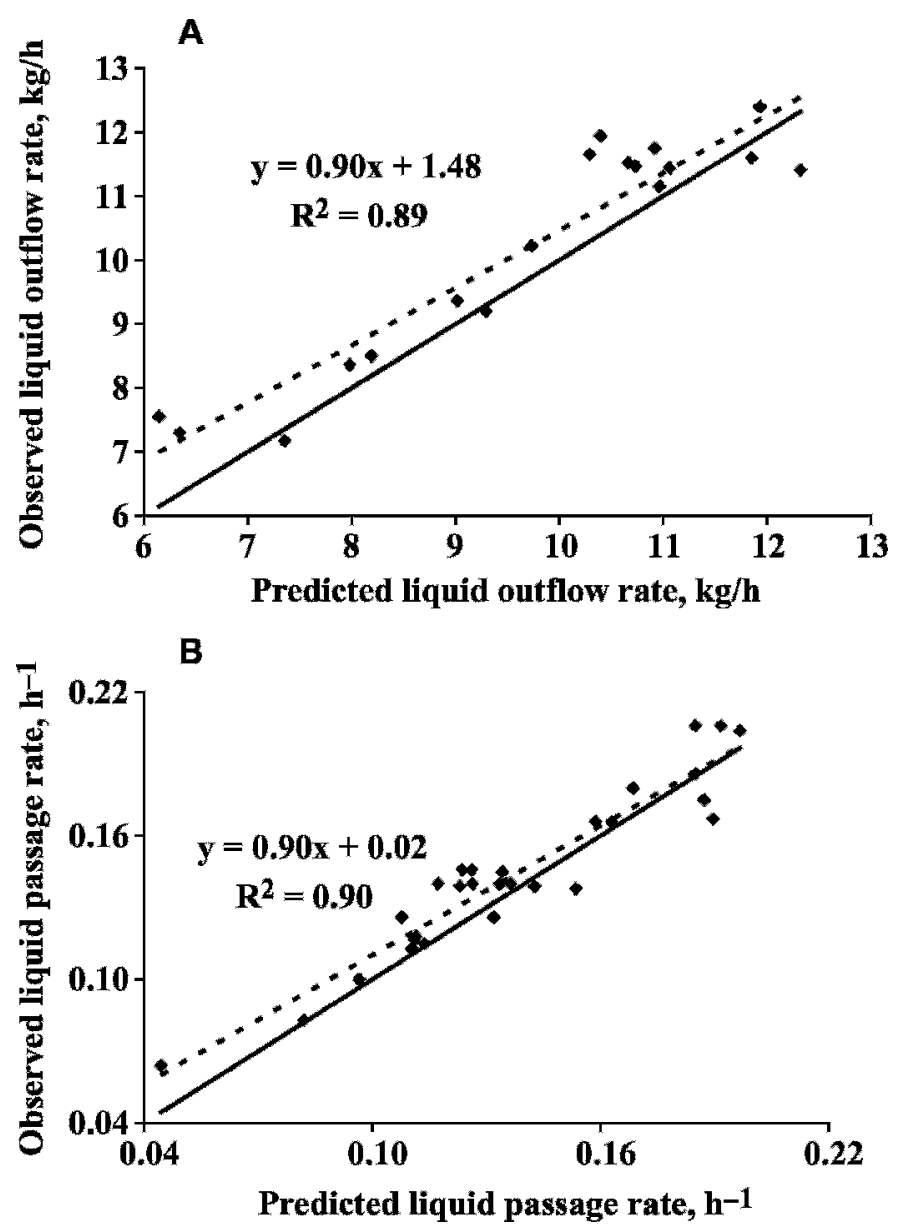

Figure 1. Plots of regressions observed on (A) the predicted liquid outflow rate $(\mathrm{kg} / \mathrm{h})$ and $(\mathrm{B})$ the fractional liquid passage rate $\left(\mathrm{h}^{-1}\right)$ through the reticulo-omasal orifice. Predicted values were output from the liquid outflow component of the model when the amount of digesta content in the rumen was known. The solid and dotted lines represent $\mathrm{y}=\mathrm{x}$ and the best-fit linear regression, respectively.

liquid outflow rate and $\mathrm{Kpl}$ were the most sensitive to DMI, followed by BW, and were not sensitive to concentrate content in the diet, dietary DM content, and ruminating time. Eating time was also important for predicting the liquid outflow rate; however, it had less influence on predicting the $\mathrm{Kpl}$. This might be due to compensation for the LOFL and liquid pool size in the rumen by increasing the water inflow into the rumen. This implies that quantifying chewing behavior is critical for understanding the liquid dynamics in the rumen, especially when we assume non-steady-state conditions in the digestive system of ruminants.

\section{DISCUSSION}

The accuracy of predicting $\mathrm{Kpl}$ by published models was low because of its high variability and lack of strong
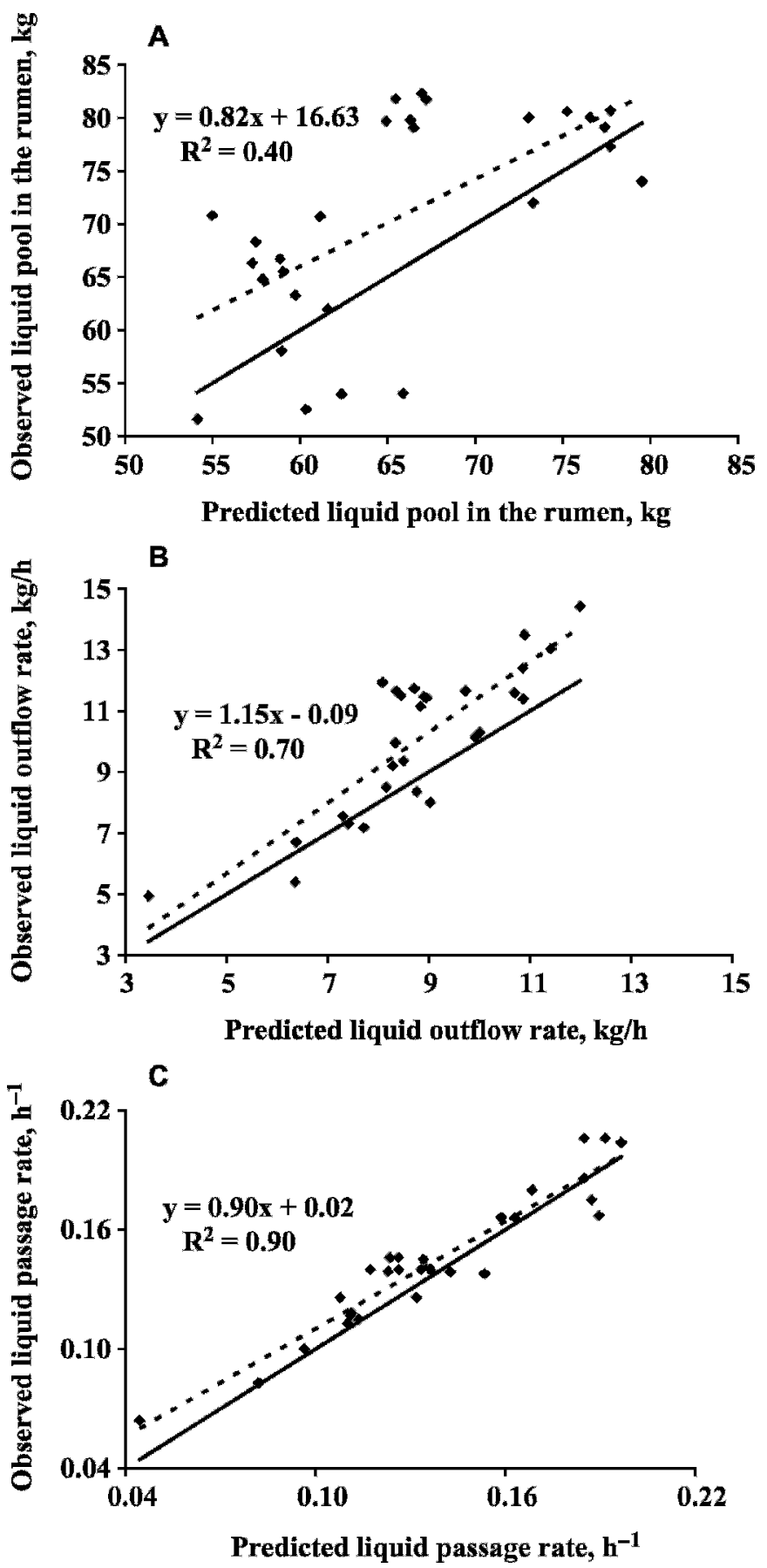

Figure 2. Plots of regressions observed on (A) the predicted daily mean liquid content in the rumen (kg), (B) the liquid outflow rate $(\mathrm{kg} / \mathrm{h})$, and $(\mathrm{C})$ the fractional liquid passage rate $\left(\mathrm{h}^{-1}\right)$ after dynamic simulations with the final whole model. The solid and dotted lines represent $\mathrm{y}=\mathrm{x}$ and the best-fit linear regression, respectively.

correlation with other variables. Seo et al. (2006b) developed an empirical equation for predicting $\mathrm{Kpl}$, with a function of forage DMI as a proportion of $\mathrm{BW}$ and concentrate DMI as a proportion of $\mathrm{BW}$ and forage DMI. 
A

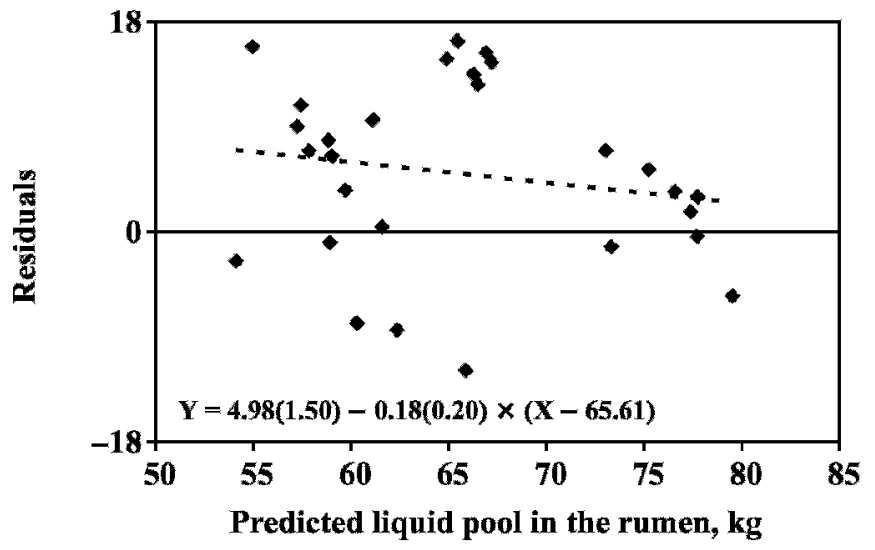

B

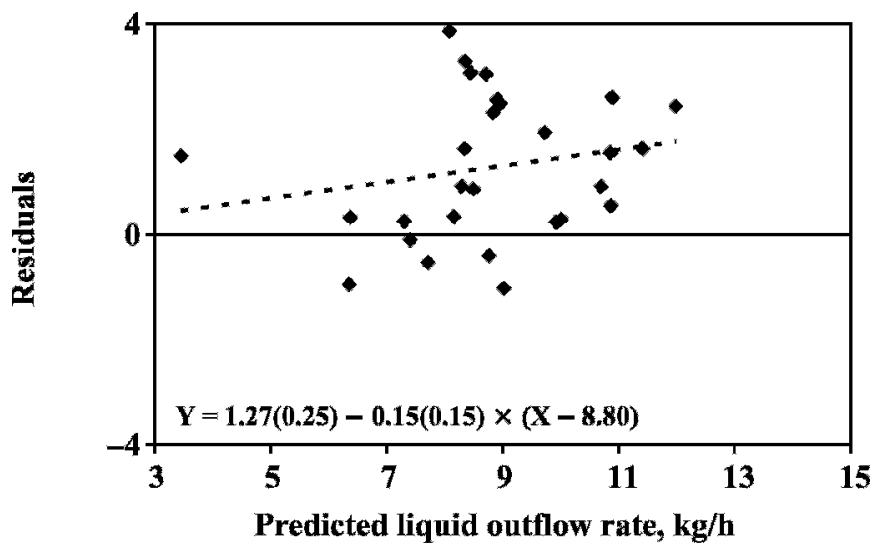

C

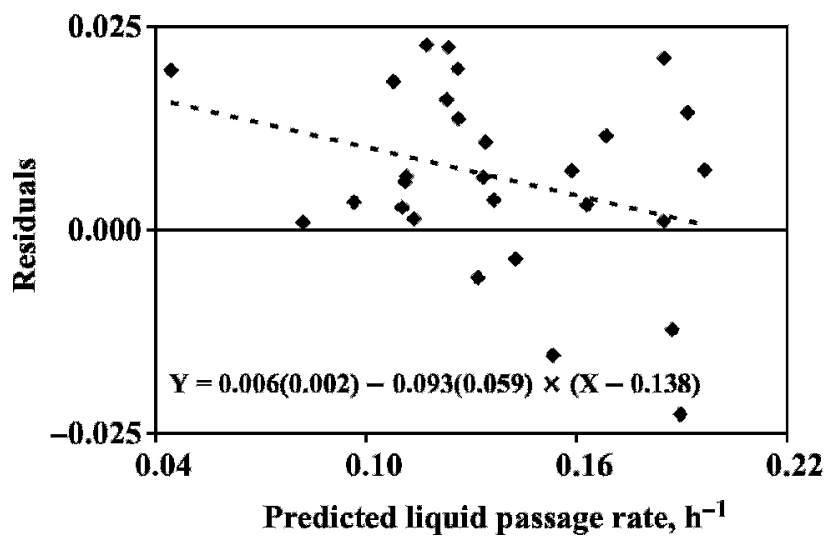

Figure 3. Plots of observed minus predicted vs. model-predicted for (A) the liquid content in the rumen $(\mathrm{kg}),(\mathrm{B})$ the liquid outflow rate $(\mathrm{kg} / \mathrm{h})$, and $(\mathrm{C})$ the fractional passage rate $\left(\mathrm{h}^{-1}\right)$ after dynamic simulations with the final whole model. The regression equations (dotted line) are presented. The predicted values were centered around the mean predicted values before the residuals $(\mathrm{Y})$ were regressed on the predicted values (X). The numbers in parentheses are standard errors of the parameter estimates. In all 3 predictions, the slope (linear bias) was not significantly different from $0(P>0.05)$, but the Y-intercept (mean bias) was significantly different from $0(P$ $<0.05)$.
This equation explained only $25 \%$ of variations in an independent database, even though it was the best among the published equations tested (Seo et al., $2006 \mathrm{~b})$. This may be not only because they were unable to account for so many other factors, but also because $\mathrm{Kpl}$ is not linear. The concept of $\mathrm{Kpl}$ implies that liquid outflow is proportional to the amount of liquid in the rumen, and thus varies linearly with the LOFR while varying inversely with the amount of liquid in the rumen:

$$
\mathrm{Kpl}=\frac{\mathrm{LOFR}}{\mathrm{LCR}}
$$

where $\mathrm{Kpl}$ is the fractional liquid passage rate $\left(\mathrm{h}^{-1}\right)$, LOFR is the liquid outflow rate $(\mathrm{kg} / \mathrm{h})$, and LCR is the liquid content in the rumen $(\mathrm{kg})$.

Many factors may influence the liquid outflow rate and liquid content in the rumen at the same time. Therefore, we developed a model to predict liquid outflow rate and liquid content in the rumen separately. This model assumed there were 2 inflows, one in-andout flow, and one outflow in the ruminal liquid system. The liquid content in the rumen was determined by the integration of dynamic flows of liquid.

Although outflow of digesta through the ROO has been known for decades to be closely related to the frequency and duration of opening of the ROO, which in turn is associated with primary reticular contractions (Balch et al., 1951), there was no attempt to incorporate these physiological findings into a model quantitatively to predict liquid flow out of the rumen. Sauvant et al. (1996) calculated the particle outflow rate as a function of the frequency of reticular contraction and outflow per contraction. In their model, reticular contraction varied only during eating time, and outflow per contraction was determined by the rumen volume. In developing our model, we attempted to identify and quantify the most critical physiological events. This resulted in the finding that the ROO should be opened more frequently than the PRC, longer than half the duration of the biphasic PRC, or both. The model assumption of a constant value for the cross-sectional area of the ROO might not be realistic, and may therefore change the result. However, there is little evidence to support a larger cross-sectional area of the ROO. The value on which our model was based was measured in adult cattle when the ROO was fully dilated (McBride et al., 1983). Furthermore, the ROO does not maintain its maximal opening during opening, and physical enlargement of the area by feed particles does not seem to be realistic, considering the DM content of the effluent digesta from the RR (4 to 6\%; Harmeyer and Michalowski, 1991). Therefore, the finding of a longer opening of 
Table 6. Sensitivity of model predictions for liquid outflow through the reticulo-omasal orifice (ROO) to variation in the frequency and amplitude of the primary reticular contraction and duration of ROO opening per one cycle of primary reticular contraction ${ }^{1}$

\begin{tabular}{lccccc}
\hline Item & Study $1^{2}$ & Study 2 & Study 3 & Study 4 & Study 5 \\
\hline $\begin{array}{l}\text { Liquid flow rate, } \mathrm{kg} / \mathrm{h} \\
\text { Mean }^{3}\end{array}$ & & & & & \\
SD & 10.73 & 10.69 & 4.81 & 3.41 & 7.99 \\
Minimum & 0.56 & 0.55 & 0.31 & 0.20 & 0.41 \\
$\quad$ Maximum & 9.08 & 9.09 & 4.09 & 2.97 & 6.80 \\
Liquid passage rate, $\mathrm{h}^{-1}$ & 12.44 & 12.37 & 5.58 & 4.05 & 9.26 \\
$\quad$ Mean & 0.166 & 0.130 & 0.089 & 0.044 & 0.108 \\
SD & 0.009 & 0.007 & 0.006 & 0.003 & 0.006 \\
Minimum & 0.140 & 0.110 & 0.076 & 0.038 & 0.092 \\
Maximum & 0.192 & 0.150 & 0.103 & 0.052 & 0.125 \\
\hline
\end{tabular}

${ }^{1} \mathrm{~A}$ uniform distribution, with $\pm 10 \%$ of the mean from the mean estimates for each simulation, was assumed for the inputs, as shown in Table 3.

${ }^{2}$ Study 1, treatment 1 in Taylor and Allen (2005a,b,c); study 2, treatment 4 in Yang et al. (2001); study 3 , treatment 3 in Woodford and Murphy (1988b); study 4, treatment 1 in Okine and Mathison (1991); study 5, treatment 4 in Maekawa et al. (2002b).

${ }^{3}$ Statistics of the predicted values from the Monte Carlo simulations until less than $1 \%$ of convergence was achieved.

the ROO within a cycle of PRC, rather than a larger opening, is still valid. Nonetheless, it is possible that the adjustment factor embeds the effect of variations in the cross-sectional area of the ROO.

Several studies support this finding. Balch et al. (1951) reported that the ROO was normally loosely opened so that it was opened about 60 to $70 \%$ of a complete contraction cycle. Bueno (1975; see also Deswysen, 1987) observed that the ROO opened for 10 to $12 \mathrm{~s}$, starting on the beginning of the second phase of PRC, and closed progressively over a total period of 15 to $25 \mathrm{~s}$. The findings of this simulation and the fact that permanent opening of the ROO only doubled the flow rate (Bueno, 1975) did not support the hypothesis of some researchers (McBride et al., 1983; Harmeyer and Michalowski, 1991; Kelly et al., 1991; Froetschel et al., 1997) that the ROO opens for a short period of time (about $3 \mathrm{~s}$ ) during or after the second phasic primary reticular contractions, or both. Deswysen and Ellis (1988) assumed that the number of large openings and

Table 7. Relative ranking of the importance of inputs related to reticular contractions in predicting the liquid flow rate $(\mathrm{kg} / \mathrm{h})$ and liquid passage rate $(\% / \mathrm{h})$ based on the standardized regression coefficients (SRC)

\begin{tabular}{lll}
\hline Rank & Input & SRC \\
\hline 1 & Frequency during resting & 0.52 \\
2 & Duration during resting & 0.52 \\
3 & Duration during ruminating & 0.34 \\
4 & Frequency during ruminating & 0.34 \\
5 & Amplitude during resting & 0.26 \\
6 & Duration during eating & 0.24 \\
7 & Frequency during eating & 0.23 \\
8 & Amplitude during ruminating & 0.17 \\
9 & Amplitude during eating & 0.12 \\
\hline
\end{tabular}

fluxes of digesta through the ROO is not equal to the number of primary reticular contractions but to the number of strong craniodorsal ruminal contractions.

Because this analysis indicated that the ROO should have opened $2.36( \pm 0.93)$ times more than the mean values, on average, we hypothesized that the movement of major digesta through the ROO occurs at least twice within one cycle of primary reticular contraction, and that one is associated with the second phase of PRC and the other with a negative pressure gradient between the omasal canal and the RR. Pressure in the omasal canal had an oscillating pattern (Ruckebusch, 1988). If lower pressure in the omasal canal is coordinated with the secondary, or sequence $B$, contraction, then we may expect a large movement of digesta through the ROO. The secondary contractions involve only the rumen and are associated with the eructation of gas (Constable et al., 1990). Because we lack evidence to support this hypothesis, further research is needed in this area.

This model assumes that DMI of the animal is known or that good estimates are available for specific production situations. Control of the DMI is a complex mechanism (Forbes, 2003). For high-producing dairy cows and growing cattle fed well-balanced diets, the demand for nutrients to meet the genetic potential for milk production is the primary factor that drives DMI (NRC, 2001). However, in most production situations worldwide, ruminants are fed a wide variety of concentrates and forages, based on the most economical production system. Under these conditions, the nutrient needs (e.g., size of the animal, level of production, plane of nutrition or body composition of the animal, and physiological status of the animal) also drive intake, but energy density of the diet, physical limits of the rumen, adequacy in 
the composition of nutrients in the diet, palatability of the diet, environmental conditions, and psychological factors affect the DMI as well. We assumed that the average daily intake in specific production situations reflects these effects.

The model predicted the liquid outflow rate and $\mathrm{Kpl}$ in an independent database remarkably well, irrespective of whether the amount of liquid was known (Figure $1 \mathrm{~A}$ and $1 \mathrm{~B}$ ) or not (Figure $2 \mathrm{~B}$ and $2 \mathrm{C}$ ), which suggests that the biological basis of the model and its prediction of the ROO opening were reasonable. Comparison with a model assuming a constant Kpl may also support this prediction. When the final model was simulated using a constant $\mathrm{Kpl}$ of $0.15 \mathrm{~h}^{-1}$ and liquid outflow rate as the product of liquid content in the rumen and $\mathrm{Kpl}$, as suggested by Argyle and Baldwin (1988), $R^{2}$ values were decreased from 0.40 to 0.13 and from 0.70 to 0.46 , and RMSPE values were increased from 9.25 to 13.15 and from 1.84 to 2.07 for predictions of liquid content in the rumen and liquid outflow rate, respectively, with the same 28 observations in the evaluation data set.

However, the prediction of liquid content in the rumen was relatively poor because the model explained only $40 \%$ of the variation, compared with $70 \%$ of the liquid outflow rate and $90 \%$ of the fractional liquid passage rate. The residual analysis for model prediction of ruminal liquid outflow through the ROO (the first phase) showed a small but significant mean bias in prediction for both liquid outflow rate and $\mathrm{Kpl}$ and a negative slope bias in Kpl. However, when a single observation [treatment 1 in Voelker and Allen (2003a,b,c)] was omitted, the slope bias was not significant in predicting $\mathrm{Kpl}$.

In addition, the final, complete model also showed significant and positive mean biases, which means it underpredicted the observations. These may be due to a large variation in liquid flux through the rumen wall. Among the estimates from data on a total of 34 experiments, the coefficient of variation of liquid flux through the rumen wall was $43 \%(4.6 \pm 2.0 \mathrm{~kg} / \mathrm{h})$. This mean and standard deviation indicate that the model was quite sensitive to variation in liquid flux through the rumen wall. About $\pm 4 \mathrm{~kg}$ of variation in the mean liquid pool size occurred within a 50\% confidence interval. However, Kpl was not affected much by variation in liquid flux through the rumen wall. This may be because of the associated variation between liquid content in the rumen and liquid outflow rate, which could explain why $\mathrm{Kpl}$ was well predicted, even though we did not account for the variation in ruminal flux in the model. Liquid flux through the rumen wall is known to depend on the osmolality in the rumen, and there were close relationships between osmolality and the VFA concentration in the rumen (Lopez et al., 1994; Zhao et al.,
1995; Lopez et al., 2003). Argyle and Baldwin (1988) predicted ruminal flux with osmotic pressure in the rumen fluid, which was a function of soluble carbohydrates, ammonia, VFA, lactate, AA, and soluble ash. Further research is needed in predicting the production of end-products from ruminal digestion as well as the dynamics of ruminal particulate matter to predict liquid dynamics in the rumen more accurately.

The sensitivity analysis showed that DMI was the most important variable for accurately predicting liquid dynamics in the rumen, which is consistent with Seo et al. (2006a,b). This may be because DMI affects the inflow of water (equations [1], [4], and [5]), liquid content in the rumen (equation [3]), and outflow of water in terms of the opening of the ROO (equations [7] and [11]). Although DMI apparently determines the total mass balance of liquid in the rumen, it should be noted that the animal controls the outflow of liquid via regulation of the opening of the ROO. In the current model, the variables that regulate the opening of the ROO were parameterized by empirical relationships. Further research on the quantitative representation of the regulation mechanism of opening of the ROO based on causeand-effect relationships may be needed, especially when an animal's voluntary intake, which is controlled by rumen fill, is being modeled (Allen, 1996).

Interestingly, the liquid outflow rate was sensitive to the time spent eating, whereas $\mathrm{Kpl}$ was not. The same explanation can be given for this as for the sensitivity of the model to liquid flux through the rumen wall. The lack of sensitivity of $\mathrm{Kpl}$ to variations in input variables makes it desirable for practical use in predicting daily digestion and passage in the rumen. Although the absolute amount of liquid pool in the rumen and the liquid outflow rate fluctuate considerably within a day, the relative proportion is less affected by variations in the input variables.

Because of the lack of biological information and our effort to keep the model simple as long as it described the process adequately at the level of our understanding, the model assumed a simple structure and used empirical relationships to parameterize some of the variables. Thus, it may be merely a simple representation of the system. However, the model developed in this study demonstrates the potential for using mechanistic and dynamic modeling to improve our understanding of the physiological processes in animal nutrition. Moreover, its accurate predictions suggest that a robust mechanistic model using inputs available in the field, can predict the escape of nutrients from the rumen more accurately, which is important in precision feeding to reduce the nutrients in manure. More research on the underlying physiological mechanism of liquid dynamics 
in and out of the rumen will improve the comprehensibility and predictability of the model.

Because only data from dairy cattle were used to parameterize this model, one should be cautious when applying it to other classes of cattle. However, the structure of the model can be applied to all classes of cattle, with modification of coefficients (reparameterization) as needed based on the data analysis.

\section{REFERENCES}

Allen, M. S. 1996. Physical constraints on voluntary intake of forages by ruminants. J. Anim. Sci. 74:3063-3075.

Argyle, J. L., and R. L. Baldwin. 1988. Modeling of rumen water kinetics and effects of rumen ph changes. J. Dairy Sci. $71: 1178-1188$.

Bailey, C. B. 1961. Saliva secretion and its relation to feeding in cattle. 3 . Rate of secretion of mixed saliva in cow during eating, with an estimate of magnitude of total daily secretion of mixed saliva. Br. J. Nutr. 15:443-451.

Bailey, C. B., and C. C. Balch. 1961a. Saliva secretion and its relation to feeding in cattle. 1. Composition and rate of secretion of parotid saliva in a small steer. Br. J. Nutr. 15:371-382.

Bailey, C. B., and C. C. Balch. 1961b. Saliva secretion and its relation to feeding in cattle. 2. Composition and rate of secretion of mixed saliva in cow during rest. Br. J. Nutr. 15:383-402.

Balch, C. C. 1952. Factors affecting the utilization of food by dairy cows. 6. The rate of contraction of the reticulum. Br. J. Nutr. 6:366-375.

Balch, C. C., and R. C. Campling. 1962. Regulation of voluntary food intake in ruminants. Nutr. Abstr. Rev. 32:669-686.

Balch, C. C., A. Kelly, and G. Heim. 1951. Factors affecting the utilization of food by dairy cows. 4 . The action of the reticuloomasal orifice. Br. J. Nutr. 5:207-216.

Bartley, E. E. 1976. Bovine saliva: Production and function. Pages 61-81 in Buffers in Ruminant Physiology and Metabolism. M. S. Weinberg and L. S. Sheffner, ed. Church and Dwight, New York, NY.

Baumont, R., M. Jailer, and J. Jamot. 1993. Estimation of the dynamics of rumen water during the meal in sheep fed lucerne hay ad libitum. Ann. Zootech. 42(2):157. (Abstr.)

Beauchemin, K. A. 1991. Ingestion and mastication of feed by dairy cattle. Pages 439-463 in The Veterinary Clinics of North America: Food Animal Practice. Vol. 7. W. B. Saunders, Philadelphia, PA.

Bibby, J., and H. Toutenburg. 1977. Prediction and improved estimation in linear models. John Wiley and Sons, New York, NY.

Bines, J. A., and A. W. F. Davey. 1970. Voluntary intake, digestion, rate of passage, amount of material in alimentary tract and behaviour in cows receiving complete diets containing straw and concentrates in different proportions. Br. J. Nutr. 24:1013-1028.

Bowman, G. R., K. A. Beauchemin, and J. A. Shelford. 2003. Fibrolytic enzymes and parity effects on feeding behavior, salivation, and ruminal pH of lactating dairy cows. J. Dairy Sci. 86:565-575.

Braun, U., and M. Gotz. 1994. Ultrasonography of the reticulum in cows. Am. J. Vet. Res. 55:325-332.

Bueno, L. 1975. Motor and digestive functions of the omasum (in French, with English abstract). PhD Dissertation, Universite Paul Sabatier de Toulouse, Toulouse, France.

Burgwaldbalstad, L. A., J. S. Caton, V. I. Burke, and K. C. Olson. 1995. Influence of forage level and naloxone injection of feedintake, digestion, and plasma-hormone and metabolite concentrations in dairy heifers. J. Anim. Sci. 73:2677-2686.

Cafe, L. M., and D. P. Poppi. 1994. The fate and behavior of imbibed water in the rumen of cattle. J. Agric. Sci. 122:139-144.

Campling, R. C., and M. Freer. 1966. Factors affecting voluntary intake of food by cows. 8. Experiments with ground pelleted roughages. Br. J. Nutr. 20:229-244.

Canale, C. J., S. M. Abrams, L. D. Muller, W. L. Kjelgaard, P. M. Anderson, and H. W. Harpster. 1988. Alkali-treated forage for early lactation dairy-cows-Effect on lactation performance and nutrient digestibility. J. Dairy Sci. 71:2166-2174.

Cassida, K. A., and M. R. Stokes. 1986. Eating and resting salivation in early lactation dairy cows. J. Dairy Sci. 69:1282-1292.

Church, D. C. 1988. Salivary function and production. Pages 117-124 in The Ruminant Animal: Digestive Physiology and Nutrition. D. C. Church, ed. Prentice-Hall, Englewood Cliffs, NJ.

Constable, P. D., G. F. Hoffsis, and D. M. Rings. 1990. The reticulorumen: Normal and abnormal motor function. Part 2. Secondary contraction cycles, rumination, and esophageal groove closure. Compend. Contin. Educ. Pract. Vet. 12:1169-1174.

Dado, R. G., and M. S. Allen. 1995. Intake limitations, feeding-behavior, and rumen function of cows challenged with rumen fill from dietary fiber or inert bulk. J. Dairy Sci. 78:118-133.

Denn, M. M. 1980. Process Fluid Mechanics. Prentice Hall, Upper Saddle River, NJ.

Deswysen, A. G., and W. C. Ellis. 1988. Site and extent of neutral detergent fiber digestion, efficiency of ruminal digesta flux and fecal output as related to variations in voluntary intake and chewing behavior in heifers. J. Anim. Sci. 66:2678-2686.

Dracy, A. E., D. E. Sander, and A. J. Kurtenba. 1972. Pressure patterns in reticulum of cow. J. Dairy Sci. 55:1156-1159.

Evans, E. 1981. An evaluation of the relationships between dietary parameters and rumen liquid turnover rate. Can. J. Anim. Sci. 61:91-96.

Faichney, G. J., D. E. Beever, and J. L. Black. 1981. Prediction of the fractional rate of outflow of water from the rumen of sheep. Agr. Syst. 6:261-268.

Fernandez, I., C. Martin, M. Champion, and B. Michalet-Doreau. 2004. Effect of corn hybrid and chop length of whole-plant corn silage on digestion and intake by dairy cows. J. Dairy Sci. 87:1298-1309.

Forbes, J. M. 2003. The multifactorial nature of food intake control. J. Anim. Sci. 81:E139-E144.

Freer, M., C. C. Balch, and R. C. Campling. 1962. Factors affecting voluntary intake of food by cows. 4 . Behaviour and reticular motility of cows receiving diets of hay, oat straw and oat straw with urea. Br. J. Nutr. 16:279-295.

Freer, M., and R. C. Campling. 1965. Factors affecting voluntary intake of food by cows. 7. Behaviour and reticular motility of cows given diets of hay dried grass concentrates and ground pelleted hay. Br. J. Nutr. 19:195-207.

Froetschel, M. A., J. K. Courchaine, S. W. Nichols, H. E. Amos, and A. C. Murry, Jr. 1997. Opioid-mediated responses to dietary protein on reticular motility and plasma insulin. J. Dairy Sci. 80:511-518.

Grimaud, P., and M. Doreau. 1995. Effect of extended underfeeding on digestion and nitrogen-balance in nonlactating cows. J. Anim. Sci. 73:211-219.

Harmeyer, J., and T. Michalowski. 1991. A technique for the collection of reticular effluent of sheep. J. Vet. Med. A. 38:107-114.

Hartnell, G. F., and L. D. Satter. 1979. Determination of rumen fill, retention time and ruminal turnover rates of ingesta at different stages of lactation in dairy-cows. J. Anim. Sci. 48:381-392.

Holteniu, P., S. O. Jacobsso, and G. Jonson. 1971. Recording of reticular motility in cattle with experimental and spontaneous traumatic reticuloperitonitis. Acta Vet. Scand. 12:325-334.

Hooper, A. P., and J. G. Welch. 1985. Change of functional specificgravity of forages in various solutions. J. Dairy Sci. 68:1652-1658.

Hristov, A. N., and G. A. Broderick. 1996. Synthesis of microbial protein in ruminally cannulated cows fed alfalfa silage, alfalfa hay, or corn silage. J. Dairy Sci. 79:1627-1637.

Johnson, T. R., and D. K. Combs. 1991. Effects of prepartum diet, inert rumen bulk, and dietary polyethylene-glycol on dry-matter intake of lactating dairy-cows. J. Dairy Sci. 74:933-944.

Johnson, T. R., and D. K. Combs. 1992. Effects of inert rumen bulk on dry matter intake in early and midlactation cows fed diets differing in forage content. J. Dairy Sci. 75:508-519.

Kelly, J. M., M. A. Froetschel, W. J. J. Crom, W. M. J. Hagler, and B. W. McBride. 1991. Effects of a parasympathomimetic agent slaframine on reticulo-omasal orifice function. Can. J. Anim. Sci. 71:321-326. 
Kil, S. J., and M. A. Froetschel. 1994. Involvement of opioid peptides from casein on reticular motility and digesta passage in steers. J. Dairy Sci. 77:111-123.

Langhans, W., R. Rossi, and E. Scharrer. 1995. Relationship between feed and water intake in ruminants. Pages 199-216 in Ruminant Physiology: Digestion, Metabolism, Growth, and Reproduction: Proc. Eighth Int. Symp. Ruminant Physiol. W. V. Engelhardt, S. Leonhard-Marek, G. Breves, and D. Giesecke, ed. Enke, Stuttgart, Germany.

Lopez, S., F. D. D. Hovell, J. Dijkstra, and J. France. 2003. Effects of volatile fatty acid supply on their absorption and on water kinetics in the rumen of sheep sustained by intragastric infusion. J. Anim. Sci. 81:2609-2616.

Lopez, Y. S., F. D. D. Hovell, and N. A. Macleod. 1994. Osmotic pressure, water kinetics and volatile fatty acid absorption in the rumen of sheep sustained by intragastric infusions. Br. J. Nutr. 71:153-168.

Maekawa, M., K. A. Beauchemin, and D. A. Christensen. 2002a. Chewing activity, saliva production, and ruminal $\mathrm{pH}$ of primiparous and multiparous lactating dairy cows. J. Dairy Sci. 85:1176-1182.

Maekawa, M., K. A. Beauchemin, and D. A. Christensen. 2002b. Effect of concentrate level and feeding management on chewing activities, saliva production, and ruminal $\mathrm{pH}$ of lactating dairy cows. J. Dairy Sci. 85:1165-1175.

Mathison, G. W., E. K. Okine, A. S. Vaage, M. Kaske, and L. P. Milligan. 1995. Current understanding of the contribution of the propulsive activities in the forestomach to the flow of digesta. Pages 23-41 in Ruminant Physiology: Digestion, Metabolism, Growth, and Reproduction: Proc. Eighth Int. Symp. Ruminant Physiol. W. V. Engelhardt, S. Leonhard-Marek, G. Breves, and D. Giesecke, ed. Enke, Stuttgart, Germany.

McBride, B. W., L. P. Milligan, and B. V. Turner. 1983. Endoscopic observation of the reticulo-omasal orifice of cattle. J. Agric. Sci. 101:749-750.

Meyer, R. M., E. E. Bartley, J. L. Morrill, and W. E. Stewart. 1964. Salivation in cattle. I. Feed and animal factors affecting salivation and its relation to bloat. J. Dairy Sci. 47:1339-1345.

Miaron, J. O. O., and R. J. Christopherson. 1992. Effect of prolonged thermal exposure on heat-production, reticular motility, rumenfluid and rumen-particulate passage-rate constants, and apparent digestibility in steers. Can. J. Anim. Sci. 72:809-819.

Norgaard, P. 1989. The influence of physical form of ration on chewing activity and rumen motility in lactating cows. Acta Agric. Scand. 39:187-202.

NRC. 2001. Nutrient Requirements of Dairy Cattle. 7th rev. ed. National Academy Press, Washington, DC.

Okine, E. K., G. R. Khorasani, and J. J. Kennelly. 1994. Effects of cereal grain silages versus alfalfa silage on chewing activity and reticular motility in early lactation cows. J. Dairy Sci. 77:1315-1325.

Okine, E. K., and G. W. Mathison. 1991. Reticular contraction attributes and passage of digesta from the ruminoreticulum in cattle fed roughage diets. J. Anim. Sci. 69:2177-2186.

Okine, E. K., G. W. Mathison, and R. T. Hardin. 1989. Effects of changes in frequency of reticular contractions on fluid and particulate passage rates in cattle. J. Anim. Sci. 67:3388-3396.

Okine, E. K., G. W. Mathison, M. Kaske, J. J. Kennelly, and R. J. Christopherson. 1998. Current understanding of the role of the reticulum and reticulo-omasal orifice in the control of digesta passage from the ruminoreticulum of sheep and cattle. Can. J. Anim. Sci. 78:15-21.

Okine, E. K., A. Tesfaye, and G. W. Mathison. 1993. Relationships between reticular contractions and digesta passage in steers consuming alfalfa hay and barley straw combinations ad libitum. J. Anim. Sci. 71:3043-3051.

Owens, F. N., and A. L. Goetsch. 1988. Ruminal fermentation. Pages 145-171 in The Ruminant Animal: Digestive Physiology and Nutrition. D. C. Church, ed. Prentice-Hall, Englewood Cliffs, NJ.

Poppi, D. P., D. J. Minson, and J. H. Ternouth. 1981. Studies of cattle and sheep eating leaf and stem fractions of grasses. 2. Factors controlling the retention of feed in the reticulo-rumen. Aust. J. Agric. Res. 32:109-121.

Putnam, P. A., R. Lehman, and R. E. Davis. 1965. Feed intake and salivary secretion by steers. J. Anim. Sci. 24:817-820.

Putnam, P. A., D. A. Yarns, and R. E. Davis. 1966. Effect of pelleting rations and hay-grain ratio on salivary secretion and ruminal characteristics of steers. J. Anim. Sci. 25:1176-1180.

Ruckebusch, Y. 1988. Motility of the gastro-intestinal tract. Pages 64-107 in The Ruminant Animal: Digestive Physiology and Nutrition. D. C. Church, ed. Prentice-Hall, Englewood Cliffs, NJ.

SAS Institute. 2002. User's Guide: Statistics. Version 9th ed. SAS Institute, Inc., Cary, NC

Sauvant, D., R. Baumont, and P. Faverdin. 1996. Development of a mechanistic model of intake and chewing activities of sheep. J. Anim. Sci. 74:2785-2802.

Sellers, A. F., and C. E. Stevens. 1966. Motor functions of the ruminant forestomach. Physiol. Rev. 46:634-661.

Seo, S., L. O. Tedeschi, C. G. Schwab, B. D. Garthwaite, and D. G. Fox. 2006a. Evaluation of the passage rate equations in the dairy Nrc (2001) model. J. Dairy Sci. 89:2327-2342.

Seo, S., L. O. Tedeschi, C. G. Schwab, C. Lanzas, and D. G. Fox. 2006b. Development and evaluation of empirical equations to predict feed passage rate in cattle. Anim. Feed Sci. Technol. 128:67-83.

Stevens, C. E., A. F. Sellers, and F. A. Spurrell. 1960. Function of the bovine omasum in ingesta transfer. Am. J. Physiol. 198:449-455.

St-Pierre, N. R. 2003. Reassessment of biases in predicted nitrogen flows to the duodenum by NRC 2001. J. Dairy Sci. 86:344-350.

Taylor, C. C., and M. S. Allen. 2005a. Corn grain endosperm type and brown midrib 3 corn silage: Feeding behavior and milk yield of lactating cows. J. Dairy Sci. 88:1425-1433.

Taylor, C. C., and M. S. Allen. 2005b. Corn grain endosperm type and brown midrib 3 corn silage: Ruminal fermentation and $\mathrm{N}$ partitioning in lactating cows. J. Dairy Sci. 88:1434-1442.

Taylor, C. C., and M. S. Allen. 2005c. Corn grain endosperm type and brown midrib 3 corn silage: Site of digestion and ruminal digestion kinetics in lactating cows. J. Dairy Sci. 88:1413-1424.

Voelker, J. A., and M. S. Allen. 2003a. Pelleted beef pulp substituted for high-moisture corn: 1 . Effects on feed intake, chewing behavior, and milk production of lactating dairy cows. J. Dairy Sci. 86:3542-3552.

Voelker, J. A., and M. S. Allen. 2003b. Pelleted beef pulp substituted for high-moisture corn: 2. Effect of digestion and ruminal digestion kinetics in lactating dairy cows. J. Dairy Sci. 86:3553-3561.

Voelker, J. A., and M. S. Allen. 2003c. Pelleted beet pulp substituted for high-moisture corn: 3. Effects on ruminal fermentation, $\mathrm{pH}$, and microbial protein efficiency in lactating dairy cows. J. Dairy Sci. 86:3562-3570.

Warner, A. C. I., and B. D. Stacy. 1968. Fate of water in rumen. 2. Water balances throughout feeding cycle in sheep. Br. J. Nutr. $22: 389$.

Woodford, S. T., and M. R. Murphy. 1988a. Dietary alteration of particle breakdown and passage from the rumen in lactating dairy-cattle. J. Dairy Sci. 71:687-696.

Woodford, S. T., and M. R. Murphy. 1988b. Effect of forage physical form on chewing activity, dry-matter intake, and rumen function of dairy-cows in early lactation. J. Dairy Sci. 71:674-686.

Woodford, S. T., M. R. Murphy, C. L. Davis, and K. R. Holmes. 1984. Ruminal bypass of drinking-water in lactating cows. J. Dairy Sci. 67:2471-2474.

Yang, W. Z., K. A. Beauchemin, and L. M. Rode. 2001. Barley processing, forage: Concentrate, and forage length effects on chewing and digesta passage in lactating cows. J. Dairy Sci. 84:2709-2720.

Yokoyama, M. T., and K. A. Johnson. 1988. Microbiology of the rumen and intestine. Pages 125-144 in The Ruminant Animal: Digestive Physiology and Nutrition. D. C. Church, ed. Prentice-Hall, Englewood Cliffs, NJ.

Zhao, G. Y., M. Duric, N. A. Macleod, E. R. Orskov, F. D. D. Hovell, and Y. L. Feng. 1995. The use of intragastric nutrition to study saliva secretion and the relationship between rumen osmoticpressure and water transport. Br. J. Nutr. 73:155-161. 


\section{APPENDIX}

The amount of liquid passed per unit of time of the ROO opening can be calculated using 2 principles of fluid dynamics (Denn, 1980):

$$
Q=A \cdot v \text { (the continuity equation), and }
$$

$$
\Delta p=\frac{1}{2} \rho \cdot v^{2} \text { (the Bernoulli equation), }
$$

where $Q$ is the flow rate $\left(\mathrm{cm}^{3} / \mathrm{s}\right), A$ is the area $\left(\mathrm{cm}^{2}\right), v$ is the fluid velocity $(\mathrm{cm} / \mathrm{s}), \Delta p$ is the pressure gradient $(\mathrm{mmHg})$, and $\rho$ is the fluid density $\left(\mathrm{g} / \mathrm{cm}^{3}\right)$. From equation [A2], we can calculate the fluid velocity based on the pressure gradient and density of the fluid:

$$
v=\sqrt{\frac{2 \Delta p}{\rho}} .
$$

Combining equations [A1] and [A3] yields

$$
Q=A \cdot \sqrt{\frac{2 \Delta p}{\rho}} .
$$

The area of ROO was estimated from the observations by McBride et al. (1983). The shape of the ROO is an ellipse $(4.5 \times 1 \mathrm{~cm})$ in a mature Holstein steer $(528 \mathrm{~kg})$ fed $6 \mathrm{~kg}$ of long alfalfa hay twice daily. Thus,

$$
\begin{gathered}
A=\frac{\pi \times \text { long_axis } \times \text { short_axis }}{4}= \\
\frac{3.14 \times 4.5 \times 1}{4}=3.53 \mathrm{~cm}^{2} .
\end{gathered}
$$

Assuming that the area is constantly $3.53 \mathrm{~cm}^{2}$, equation [A4] becomes

$$
Q=A \cdot \sqrt{\frac{2 \Delta p}{\rho}}=3.53 \cdot \sqrt{\frac{2 \Delta p}{1.0}}=5.0 \sqrt{\Delta p} .
$$

The amount of liquid flow per unit of time of the ROO opening $(\mathrm{g} / \mathrm{s})$ is equivalent to the flow rate $(\mathrm{mL} /$ $\mathrm{s})$ because the specific gravity of ruminal liquid is close to 1.0 (Hooper and Welch, 1985). Therefore, we can substitute Q with LFRO:

$$
\mathrm{LFRO}=5.0 \sqrt{\Delta p},
$$

where LFRO is the amount of liquid flow per second of $\mathrm{ROO}$ opening and $\Delta p$ is the pressure gradient between the reticulum and omasum $(\mathrm{mmHg})$.

It is not experimentally easy to estimate the pressure gradient between the reticulum and omasum. Instead, most data in the literature are measurements of the increase in reticular pressure associated with contractions. Stevens et al. (1960) measured a 10-mmHg pressure difference at each end of the orifice, which was similar to the reported value of the amplitude of PRC. Therefore, in this model, we assumed that the pressure gradient between the reticulum and omasum was the same as the amplitude of the second phasic primary contraction of the reticulum. Therefore, equation [A6] becomes equation [10]. 